\title{
Erratum to: Lanthanum-induced neurotoxicity: solving the riddle of its involvement in cognitive impairment?
}

\author{
Apostolos Zarros • Ashleigh-Maria Byrne • \\ Stephanie D. Boomkamp · Stylianos Tsakiris • \\ George S. Baillie
}

Published online: 8 August 2014

(C) Springer-Verlag Berlin Heidelberg 2014

Erratum to: Arch Toxicol (2013) 87: 2031-2035

DOI 10.1007/s00204-013-1112-7

Due to an unfortunate oversight, a mistake was made in the Fig. 1 legend (p. 2033). Readers should note that the elements in blue colour are reported to be up-regulated/activated/increased, while the elements highlighted in red colour are reported to be down-regulated/inhibited/decreased following in vivo exposure to $\mathrm{La}^{3+}$, not the other way round as falsely indicated.

The online version of the original article can be found under doi:10.1007/s00204-013-1112-7.

A. Zarros $(\bowtie) \cdot$ A.-M. Byrne $\cdot$ G. S. Baillie

Gardiner Laboratory (535), Wolfson Link Building,

College of Medical, Veterinary and Life Sciences, Institute

of Cardiovascular and Medical Sciences, University of Glasgow,

Box 318, 111 West George Str., Glasgow G2-1QX, Scotland, UK

e-mail: a.zarros.1@ research.gla.ac.uk

\section{A. Zarros $\cdot$ S. Tsakiris}

Laboratory of Physiology, Medical School, National

and Kapodistrian University of Athens, Athens, Greece

\section{S. D. Boomkamp}

Strathclyde Institute of Pharmacy and Biomedical Sciences,

University of Strathclyde, Glasgow, Scotland, UK 